\title{
Effect of personality on the emotional response elicited by wines
}

\author{
María Mora, Elena Urdaneta, Carolina Chaya
}

\begin{abstract}
A B S T R A C T
Studies related to the measurement of the emotional response and its relationship with preferences and consumer behavior are gaining relevance in the last years. Some of them have highlighted the influence of individual factors, such as personality, on the evoked emotions. The current study examined the relationship between personality traits and the emotions elicited by different wine samples. Six wines were assessed by 175 consumers in terms of hedonic and emotional response, using 9-point scale and EsSense25 respectively. Consumers were clustered into four personality segments according to their personality traits which were determined using the Big Five Inventory method. Results showed an association between the psychological profile and the elicited emotions. A strong effect of personality on the emotional response elicited by the wine samples was found on 14 emotions. In addition, a significant effect was found for six emotions when studying the sample effect. The main relationships between personality and emotions were found in two consumers' segments: G1 characterized by higher ratings on the Neuroticism dimension, was more related to negative emotions than G4. On the contrary, G4, defined by higher ratings on Extraversion, Agreeableness, and Consciousness, was more related to positive emotions than G1. No significant interactions between wine and personality were identified, meaning that the effect of personality did not change significantly across wines. Splitting the consumers' panel depending on their personality profile allowed obtaining a deeper overview and a further understanding of the emotions evoked by wines.
\end{abstract}

\section{Introduction}

Success in product development is related to understanding how consumers act and how their behavior is defined. In the last years, sensory research has been extended towards the study of consumers' insights and some new methods have been proposed to investigate the influence of different factors in the decision-making process (Köster, 2009). Some of these factors are based on psychological concepts, and need to be considered to understand how eating and drinking behavior, and also food choice of consumers, are defined (Köster, 2009).

Mojet (2001) classified these psychological factors in three main groups: i) cognition, emotion, motivation, and decision-making, ii) memory, previous experiences, and learning, and iii) neophobia and personality traits. Emotional response has been one of the most studied psychological factors to understand consumers' food choice and preferences during the past decade (Prescott, 2017). Damasio (2006) reported that unconscious emotions played an important role in the decision-making process. Emotions elicited by odors and flavors are powerful drivers of behavior, key to promote preferences, and also to strengthen memories (R. S. Herz, 2005; Prescott, 2017; Sugiyama et al., 2015; Yeomans, Prescott, \& Gould, 2009). However, few works have reported information about the influence of individual differences on emotions, which might be relevant in the decision making process (Köster, 2009; Prescott, 2017; Spinelli, 2017). Prescott (2017) pointed out that the expression of emotions could be affected by a wide variety of individual factors such as age, education, culture, socio-economic status, and personality. Up to date, just few works have studied these effects (Mora, Urdaneta, \& Chaya, 2018; Torrico et al., 2018). Thus, to study consumer behavior and emotions, the Fallacy of Uniformity needs to be considered: people's behavior differs in degree, but not in essence. Köster (2009) put in evidence this fallacy arguing that studies which averaged consumers could provide misleading data when the results are based on bimodal or even multi-modal distributions that reflect different underlying behaviors. Personality might be one of these underlying individual factors leading to different behaviors.

In psychology, personality is described as traits which capture 
Table 1

Description of wine samples used in the present study.

\begin{tabular}{|c|c|c|c|c|c|}
\hline Code & Type of wine & Grape & Aging & PDO & Alcohol content v/v (\%) \\
\hline 1 & White & Verdejo & Young (2015) & Rueda & 13.5 \\
\hline 2 & White & Chardonnay & Young (2015) & Navarra & 13 \\
\hline 3 & Rosé & Garnacha & Young (2015) & Navarra & 13.5 \\
\hline 4 & Red & Tempranillo & Reserva (2012) & Rioja & 12.5 \\
\hline 5 & Red & Tempranillo & Reserva (2013) & Rioja & 13.5 \\
\hline 6 & Red & Tempranillo & Reserva (2012) & Ribera del Duero & 14 \\
\hline
\end{tabular}

NOTE: see Mora et al. (2018), for sensory description.

"patterns of thinking, feeling, and behaving" (APA, 2018). Authors such as Köster (2009) and Keller and Siegrist (2015), reported that personality could influence people's food choice. Keller and Siegrist (2015) studied the effect of personality in consumers' food choices showing that individuals' personality significantly affected respondents' preferences for different kinds of products such as meat, fruit, vegetables, sweets, and savory foods. Other authors, as Spinelli et al. (2018), Robino et al. (2016), Byrnes and Hayes (2013), Ullrich, Touger-Decker, O'Sullivan-Maillet, and Tepper (2004) and Stone and Pangborn (1990) explored the influence of personality traits on hedonic response. Spinelli et al. (2018) studied the role of personality on liking and choice of pungent foods, and found a relationship among different personality traits and liking. Personality traits which liked significantly more pungent foods were high sensitivity to reward, low food neophobia, low sensitivity to disgust, and low sensitivity to punishment. Also, Robino et al. (2016) confirmed the relationship among alexithymia, intensity perception, and acceptance of the bitter taste using PROP as stimulus. Regarding emotions, Prescott (2017) pointed out that personality traits, such as granularity or alexithymia, had an impact on the perceived or elicited emotions. Also, Scott, Burgess, and Tepper (2019), Samant and Seo (2018), and Herz (2011) found that taste perception, hedonic and emotional responses were affected by the personality traits. Scott et al. (2019) found that the acceptance of pungent spices was highly related to 1) PROP taster status, 2) personality traits such as sensation seeking and food adventurousness, and 3) emotions as wellbeing and disgust.

One of the most popular structures to define personality traits is the "Big Five" or "Five Factors" Model (Goldberg, 1990). This model has five dimensions: Openness (O), Conscientiousness (C), Extraversion (E), Agreeableness (A), and Neuroticism (N). The "Openness to experiences" factor is related to be open or skeptic to novelty, and to the flexibility in emotions and ideas. The "Conscientiousness" dimension refers to aptitude for being organized and hardworking. The "Extraversion" factor is described by the inclination to be sociable and extraverted. The "Agreeableness" dimension is related to traits that define whether an individual is cooperative, and sympathetic. The last factor "Neuroticism" includes aptitudes related to emotional instability.

Many authors such as Letzring and Adamcik (2015) and DeNeve and Cooper $(1998 \mathrm{a}, \mathrm{b})$ studied the relationship between the Big Five and emotions or affects. Their findings showed that the Extraversion dimension was positively related to positive affect or emotions, and the Neuroticism dimension was positively related to negative affect or emotions. This relationship was investigated also by Larsen and Ketelaar (1991) who concluded that extraverts were more receptive to positive mood induction such as rewards, and neurotics were more receptive to negative mood induction such as punishments. Also, Letzring and Adamcik (2015) examined the relationship of the negative and positive affects with the other Big Five traits, revealing that Agreeableness was negatively related to negative affect or emotions, while Conscientiousness and Openness were positively related to positive affect or emotions. In relation with the study of the personality's effect on the food elicited emotions, Samant and Seo (2018) provided evidences that the traits Extraversion and Neuroticism affected the emotional responses and contributed to predict overall liking and preferences of basic taste stimuli.
The hypothesis of the present study was that personality had an impact on the emotions elicited by wines.

Thus, the main objective on the present study was to find out the relationship between personality traits and emotional responses elicited by different wine samples. Up to date, no studies have been published which provide data related to the effect of the Big Five traits on liking and emotional response elicited by commercial beverages.

\section{Materials and methods}

\subsection{Wines selection}

Wines selection (Table 1) was based on three different criteria to cover a wide range of sensory properties: 1) type of wine, 2) type of grape and 3) wine ageing. Wines were characterized by a trained panel. The descriptive analysis was previously reported in Mora et al. (2018).

\subsection{Consumer evaluation}

A consumer panel of 175 volunteers, $48 \%$ men $(n=84)$ and $52 \%$ women $(n=91)$, range age from 18 to 70 years old, was recruited to conduct the consumer study. The screening was conducted taking into consideration that participants had to consume wine at least once per month. All tests were conducted in the tasting room of the Universidad Politécnica de Madrid. The room is equipped with individual booths and controlled light and temperature conditions $\left(21^{\circ} \mathrm{C}\right)$.

The tasting day, consumers were first asked to fill out a sociodemographic form. Second, they completed the Big Five Inventory questionnaire (BFI) (John \& Srivastava, 1999). The BFI is a self-reported questionnaire designed to measure the Big Five dimensions of the personality: Openness (O), Conscientiousness (C), Extraversion (E), Agreeableness (A), and Neuroticism (N). Participants were asked to rate the 44 statements of the BFI (Table 2) on a 5-point scale (from $1=$ strongly disagree to $5=$ strongly agree). A Spanish translated version of the questionnaire was provided by Berkeley Personality Lab (John, 2007). Because the questionnaire was translated into a LatinAmerican Spanish, a slight modification was done to adapt the questionnaire for Spaniards (back-translation procedure). Cronbach's alpha was used to confirm the internal consistency of the different dimensions.

After completing the forms, wine samples $(15 \mathrm{ml})$ were served simultaneously, all of them labelled with three-digit random codes. The first sample was always the same and was used as a warm-up sample to avoid the first position effect (Dorado, Pérez-Hugalde, Picard, \& Chaya, 2016; Wakeling \& MacFie, 1995). The presentation order of the other six wine samples was randomly assigned. After tasting each wine, consumers were asked to rate their liking degree using a 9-point hedonic scale, anchored at: $1=$ dislike extremely, $5=$ neither like nor dislike, and $9=$ like extremely. Then, consumers were asked to rate the emotions elicited by the sample, because it has been suggested that rating emotions before liking could bias the hedonic score (King, Meiselman, \& Thomas Carr, 2013).

For the emotions questionnaire, a Spanish validated version of the EsSense25 (Dorado et al., 2016; Nestrud, Meiselman, King, Lesher, \& 
Table 2

Big Five Inventory items.

\begin{tabular}{|c|c|c|}
\hline & Original questionnaire & Translated questionnaire \\
\hline 1 & Is talkative & Es locuaz, comunicativo \\
\hline 2 & Tends to find fault with others & Tiende a ser criticón \\
\hline 3 & Does a thorough job & Es minucioso en el trabajo \\
\hline 4 & Is depressed, blue & Es depresivo, melancólico \\
\hline 5 & Is original, comes up with new ideas & Es original, se le ocurren ideas nuevas \\
\hline 6 & Is reserved & Es reservado \\
\hline 7 & Is helpful and unselfish with others & Es generoso y ayuda a los demás \\
\hline 8 & Can be somewhat careless & Puede a veces ser algo descuidado \\
\hline 9 & Is relaxed, handles stress well & Es calmado, controla bien el estrés \\
\hline 10 & Is curious about many different things & Tiene intereses muy diversos \\
\hline 11 & Is full of energy & Está lleno de energía \\
\hline 12 & Starts quarrels with others & Inicia disputas con los demás \\
\hline 13 & Is a reliable worker & Es un trabajador cumplidor digno de confianza \\
\hline 14 & Can be tense & Con frecuencia se pone tenso \\
\hline 15 & Is ingenious, a deep thinker & Es ingenioso, analítico \\
\hline 16 & Generates a lot of enthusiasm & Irradia entusiasmo $^{\text {thetr }}$ \\
\hline 17 & Has a forgiving nature & Es indulgente, no le cuesta perdonar \\
\hline 18 & Tends to be disorganized & Tiende a ser desorganizado \\
\hline 19 & Worries a lot & Se preocupa mucho por las cosas \\
\hline 20 & Has an active imagination & Tiene una imaginación activa \\
\hline 21 & Tends to be quiet & Tiende a ser callado \\
\hline 22 & Is generally trusting & Es generalmente confiado \\
\hline 23 & Tends to be lazy & Tiende a ser perezoso \\
\hline 24 & Is emotionally stable, not easily upset & Es emocionalmente estable, difícil de alterar \\
\hline 25 & Is inventive & Es inventivo \\
\hline 26 & Has an assertive personality & Es asertivo, no teme expresar lo que opina \\
\hline 27 & Can be cold and aloof & Es a veces frío y distante \\
\hline 28 & Perseveres until the task is finished & Persevera hasta terminar el trabajo \\
\hline 29 & Can be moody & Es voluble, de humor cambiante \\
\hline 30 & Values artistic, aesthetic experiences & Valora lo artístico, lo estético \\
\hline 31 & Is sometimes shy, inhibited & Es a veces tímido, cohibido \\
\hline 32 & Is considerate and kind to almost everyone & Es considerado y amable con casi todo el mundo \\
\hline 33 & Does things efficiently & Hace las cosas de manera eficiente \\
\hline 34 & Remains calm in tense situations & Mantiene la calma en situaciones difíciles \\
\hline 35 & Prefers work that is routine & Prefiere trabajos que son rutinarios \\
\hline 36 & Is outgoing, sociable & Es extrovertido, sociable \\
\hline 37 & Is sometimes rude to others & Es a veces maleducado con los demás \\
\hline 38 & Makes plans and follows through with them & Hace planes y los lleva a cabo \\
\hline 39 & Gets nervous easily & Se pone nervioso con facilidad \\
\hline 40 & Likes to reflect, play with ideas & Le gusta reflexionar, jugar con las ideas \\
\hline 41 & Has few artistic interests & Tiene pocos intereses artísticos \\
\hline 42 & Likes to cooperate with others & Le gusta cooperar con los demás \\
\hline 43 & Is easily distracted & Se distrae con facilidad \\
\hline 44 & Is sophisticated in art, music, or literature & Tiene conocimientos de arte música o literatura \\
\hline
\end{tabular}

* Source: John, O. P., \& Srivastava, S. (1999). The Big Five trait taxonomy: History, measurement, and theoretical perspectives. Handbook of Personality: Theory and Research, 2 (1999), 102-138.

** Source: John, O. P. (2007). Berkeley Personality Lab. Retrieved November 9, 2018, from https://www.ocf.berkeley.edu/ johnlab/index. htm.

*** Back-translated terms to Spaniards consumers.

Cardello, 2016) was used to study consumers' response. An additional term, "curious", was included because it was reported to be an important emotion elicited by wine (Cuesta, Chaya, \& Pérez, 2010). FIZZ software (Biosystemes, Dijon, France) was used to create the questionnaire and collect the data. Emotions were randomized for each consumer, but the same order was always kept for each consumer across the different samples. Each emotion was rated on a $10 \mathrm{~cm}$ linear scale anchored at $0.5 \mathrm{~cm}$ from the line ends, from "very low" to "very high". Water and breadsticks were provided for palate cleansing between samples, and consumers were asked to wait for a minimum of $1 \mathrm{~min}$ between products to minimize carry-over effects.

\subsection{Data analysis}

As described above, BFI questionnaire contained 44 items classified into five different dimensions. Internal consistency of each dimension was verified by means of the Cronbach's alpha (values $>0,8$ ). Means of every dimension were computed for each consumer and a matrix was built: consumers were the "observations" (rows) and the dimensions were the "variables" (columns). Individual consumer ratings on the aggregated BFI dimensions were input to Hierarchical Cluster Analysis (HCA). Consumers were grouped in clusters using Euclidean distance and the Ward's criterion to obtain personality consumers' groups. $\chi^{2}$ tests were used to verify the independence of the consumers' distribution of personality groups by age and gender. XLSTAT (2018.7 version, New York, USA) (Addinsoft, 2019) was used to conduct the analysis. Significant differences among personality groups were verified by 1 way ANOVA performed on each personality dimension. Personality group was the main factor and consumers' means of each personality dimension were the dependent variables. Statgraphics (Centurion XVII version, The Plains, VA, USA) was used to conduct the analysis.

To compare the effect of personality on liking and emotional response elicited by wines, 2-way ANOVAs followed by Tukey test were performed for the significant factors. The factors "wine" and "personality group", and the 2-way interaction "wine"personality group" were included in the 2-way ANOVA models. Statgraphics (Centurion XVII 
Table 3

p-values of the 2-way ANOVA on hedonic and emotional response.

\begin{tabular}{|c|c|c|c|}
\hline Items & Wine & Personality & Wine" Personality \\
\hline Hedonic & $0.0332^{*}$ & $0.0170^{*}$ & 0.8946 \\
\hline Active & 0.6680 & $0.0360^{*}$ & 0.3665 \\
\hline Adventurous & 0.6219 & $0.0001^{\text {**t }}$ & 0.7666 \\
\hline Aggressive & $<0.0001^{* \star *}$ & 0.3625 & 0.9557 \\
\hline Bored & 0.9258 & $0.0008^{k * k}$ & 0.2106 \\
\hline Calm & 0.6962 & 0.3054 & 0.8143 \\
\hline Disgusted & 0.5223 & $0.0250^{*}$ & 0.7520 \\
\hline Enthusiastic & 0.2812 & $0.0061^{\text {**k }}$ & 0.7502 \\
\hline Free & 0.2129 & $0.0405^{*}$ & 0.7496 \\
\hline Good & 0.0597 & 0.2294 & 0.8587 \\
\hline Good natured & 0.2342 & 0.5373 & 0.9986 \\
\hline Guilty & 0.9541 & 0.2194 & 0.8862 \\
\hline Happy & $0.0403^{*}$ & $0.0006^{\text {w*t }}$ & 0.9679 \\
\hline Interested & 0.4164 & 0.2820 & 0.5149 \\
\hline Joyful & $0.0316^{*}$ & $0.0002^{\text {k* }}$ & 0.9942 \\
\hline Loving & 0.4720 & $0.0028^{\text {**k }}$ & 0.9342 \\
\hline Mild & $<0.0001^{k *}$ & 0.0688 & 0.8608 \\
\hline Nostalgic & 0.7380 & 0.9230 & 0.9547 \\
\hline Pleasant & $0.0177^{*}$ & $0.0044^{\text {wit }}$ & 0.7658 \\
\hline Satisfied & 0.5592 & $0.0008^{\text {*kt }}$ & 0.8522 \\
\hline Secure & 0.5907 & 0.4450 & 0.4919 \\
\hline Tame & 0.2606 & $0.0153^{*}$ & 0.8176 \\
\hline Understanding & 0.4451 & 0.7114 & 0.9417 \\
\hline Warm & 0.3781 & $0.0005^{\text {*k* }}$ & 0.8153 \\
\hline Wild & 0.3693 & 0.1468 & 0.6527 \\
\hline Worried & 0.5741 & $0.0013^{\text {k*k }}$ & 0.9574 \\
\hline Curious & 0.3774 & 0.2434 & 0.6155 \\
\hline
\end{tabular}

", ${ }^{* *}$ significant $\mathrm{p} \leq 0.05, \mathrm{p} \leq 0.01$ respectively.

version, The Plains, VA, USA) was used to conduct the analysis.

To summarize the emotional map elicited by the samples, and relate it to the personality dimensions, a Principal Component Analysis (PCA) was carried out using the means of the significantly different emotions identified among consumers' personality segments. XLSTAT (2018.7 version, New York, USA) (Addinsoft, 2019) was used to conduct the analysis.
Table 4

Results of ANOVA and Tukey test of personality group (G1 to G4) on the dimensions of the Big Five.

\begin{tabular}{llllll}
\hline Dimension & p-value & G1 & G2 & G3 & G4 \\
\hline Extraversion & $<0.0001$ & $3.35 \mathrm{a}$ & $4.22 \mathrm{~b}$ & $5.08 \mathrm{c}$ & $5.72 \mathrm{~d}$ \\
Agreeableness & $<0.0001$ & $4.00 \mathrm{a}$ & $5.56 \mathrm{c}$ & $5.11 \mathrm{~b}$ & $6.03 \mathrm{~d}$ \\
Consciousness & $<0.0001$ & $4.90 \mathrm{ab}$ & $5.11 \mathrm{~b}$ & $4.47 \mathrm{a}$ & $5.73 \mathrm{c}$ \\
Neuroticism & $<0.0001$ & $4.46 \mathrm{c}$ & $3.42 \mathrm{~b}$ & $4.24 \mathrm{c}$ & $2.98 \mathrm{a}$ \\
Openness & $<0.0001$ & $4.42 \mathrm{a}$ & $4.82 \mathrm{ab}$ & $5.09 \mathrm{~b}$ & $5.84 \mathrm{c}$ \\
\hline
\end{tabular}

Groups not sharing the same letter within the same row (dimension) are significantly different ( $\mathrm{p}$-value $\leq 0.05$ ).

\section{Results}

\subsection{Effect of wine samples on the hedonic and emotional response of consumers}

The univariate analysis showed that a significant effect of wine was found on the hedonic response $(\mathrm{p}<0.05)$. Also, the effect of wine samples in the elicited emotions was significant on 5 of the 26 evaluated emotions: aggressive, happy, joyful, mild, and pleasant (Table 3).

\subsection{Effect of consumers' personality on the hedonic and emotional response elicited by wines}

Consumers were grouped, depending on their personality, using the results of the BFI questionnaire. Hierarchical Cluster Analysis segmented consumers into four clusters: $G 1(n=20), G 2(n=70), G 3$ $(\mathrm{n}=46)$, and G4 $(\mathrm{n}=37)$ (Fig. 1). Although ANOVA and Tukey tests revealed that all dimensions were significantly different between consumers' groups (Table 4), the main differences on personality were found between two groups: G1, characterized by rating higher scores in the Neuroticism dimension and lower on Extraversion and Agreeableness, and G4, characterized by rating higher scores on the Extraversion, Agreeableness, and Consciousness dimensions and lower on Neuroticism. Clusters 2 and 3 presented in-between characteristics.

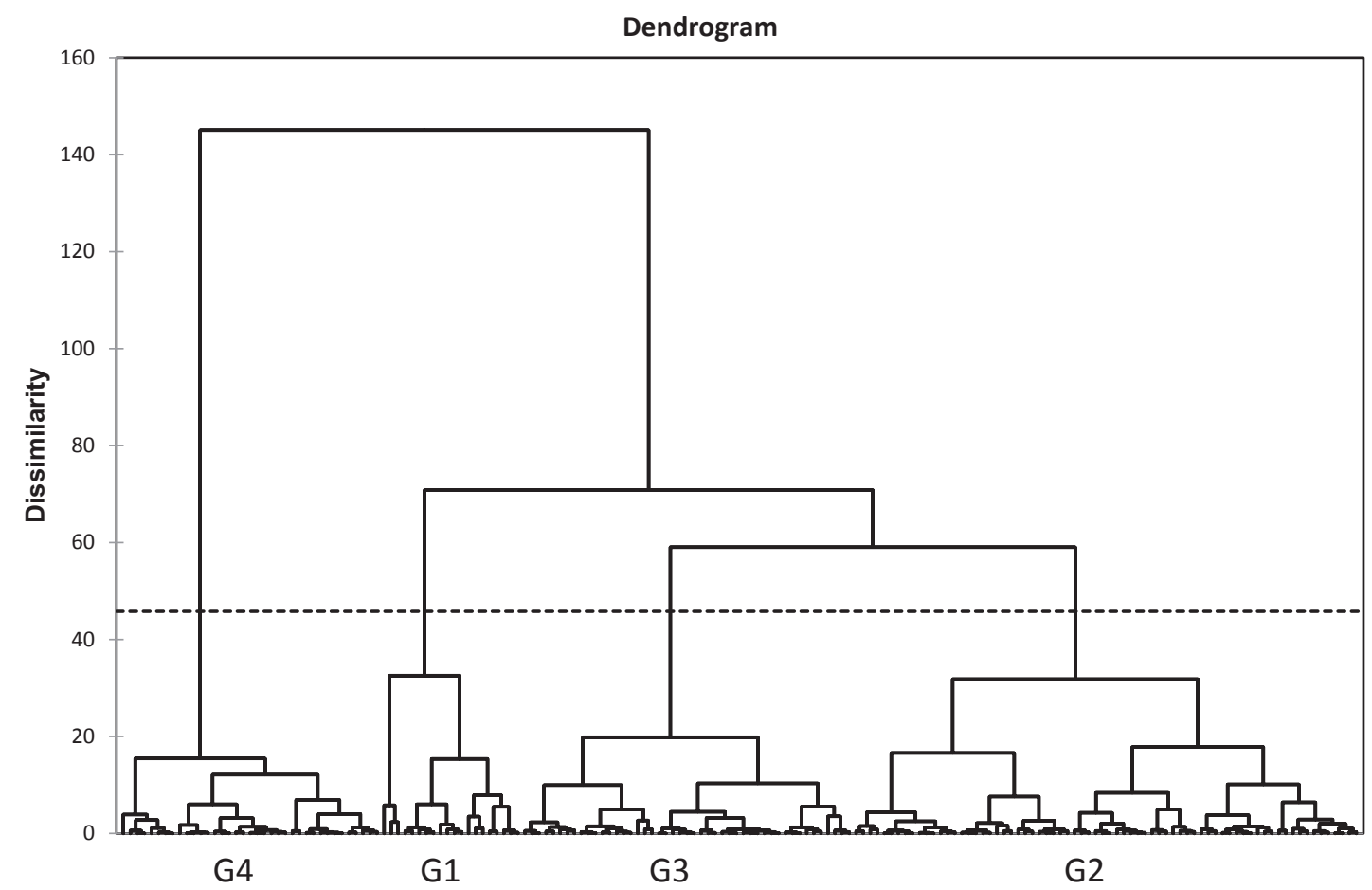

Fig. 1. Dendrogram of the cluster analysis of consumers based on the BFI dimensions. 


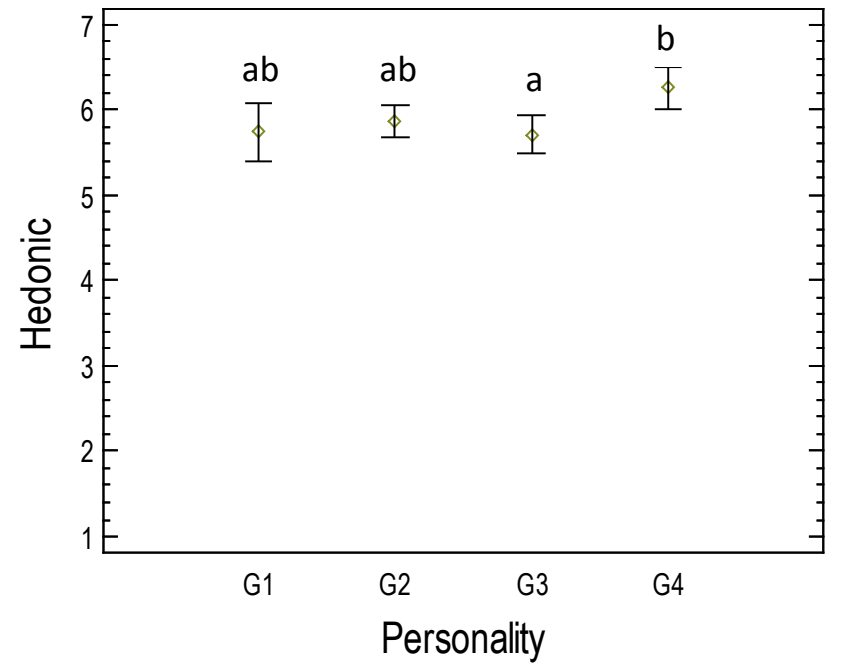

Fig. 2. Effect of the personality group (G1-G4) on liking. Personality groups not sharing the same letter are significantly different ( $\mathrm{p}$-value $\leq 0.05$ ).

The Chi square test revealed independence of the personality groups consumers' distribution by age and gender (p-values 0.28 and 0.91 respectively).

ANOVA results showed a strong effect of the personality group on liking and on 14 positive and negative emotions: active, adventurous, bored, disgusted, enthusiastic, free, happy, joyful, loving, pleasant, satisfied, tame, warm and worried (Table 3). Regarding to the hedonic response, Fig. 2 shows that G4 reported higher ratings in liking if compared with G1. Clusters G1 and G4 showed reverse behavior in the elicited emotions: positive emotions such as active, adventurous, enthusiastic, happy, joyful, loving, satisfied, and warm received higher scores by group 4 (e.g.: Enthusiastic Fig. 3a), meanwhile personality group 1 rated with significantly higher scores negative emotions such as bored, worried, and disgusted (e.g.: Bored Fig. 3b).

No statistically significant interactions between wine and personality segments on the hedonic and emotional response were found (Table 3). The effect of personality in the emotions elicited by wine did not change significantly across wines. Fig. 4 shows an example of the effect of personality on loving emotion. Hedonic and emotional response to all wines by the different personality groups of consumers can be found in Supplementary materials.

The PCA showed a relationship between the emotions elicited by all wines and the different consumers' personality groups. The first two Principal Components of the PCA explained $97.46 \%$ of the data

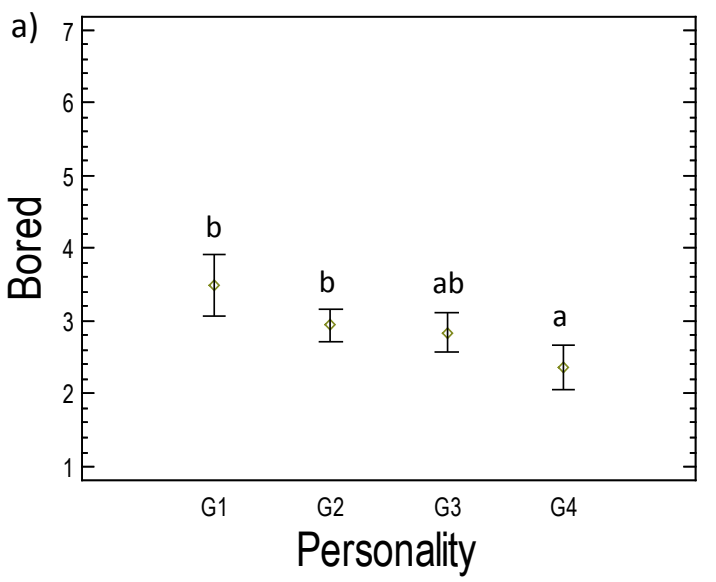

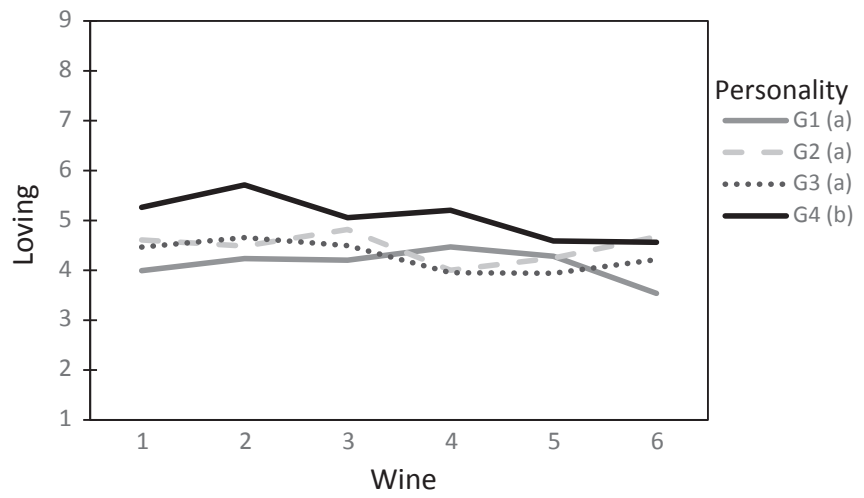

Fig. 4. Effect of personality group (G1-G4) on loving emotion evoked by the different wine samples. Personality groups not sharing the same letter are significantly different ( $\mathrm{p}$-value $\leq 0.05$ ).

variance. Fig. 5 biplot shows the projection of the personality groups, and the correlation of emotions with the first two principal components (PC1 and PC2). PC1, with higher contributions of G4 (69.7\%) and G1 (21.9\%), seems to follow a general trend, apparently separating negative (aggressive, worried, disgusted, bored and tame) from positive (enthusiastic, adventurous, active, loving, joyful, satisfied, free, pleasant, happy, warm and mild) emotions. It is to note that emotional terms included in the analysis were significantly different across personality groups. G1, characterized by higher ratings on Neuroticism dimension, was located closer to the negative emotions than G4. On the contrary, G1, characterized by having higher ratings on Extraversion, Agreeableness, and Consciousness, was positioned closer to the positive emotions. The first dimension (88.61\%) was positively correlated with pleasant emotions such as satisfied (0.979), happy (0.975), pleasant (0.953), and enthusiastic (0.881), and negatively correlated to unpleasant emotions, such as disgusted $(-0.991)$, worried $(-0.955)$, bored $(-0.890)$ and aggressive $(-0.921)$. The second dimension $(8.85 \%)$ was correlated to the level of engagement/activation of the emotions. It was positively correlated to less engaging/activated emotions such as tame (0.571), and negatively correlated to more engaging/activated emotions such as adventurous $(-0.413)$.

\section{Discussion}

The aim of this research was to investigate the influence of consumers' personality on the emotions elicited by products such as wine. Results showed an association among the psychological profile, the hedonic response, and the elicited emotions.

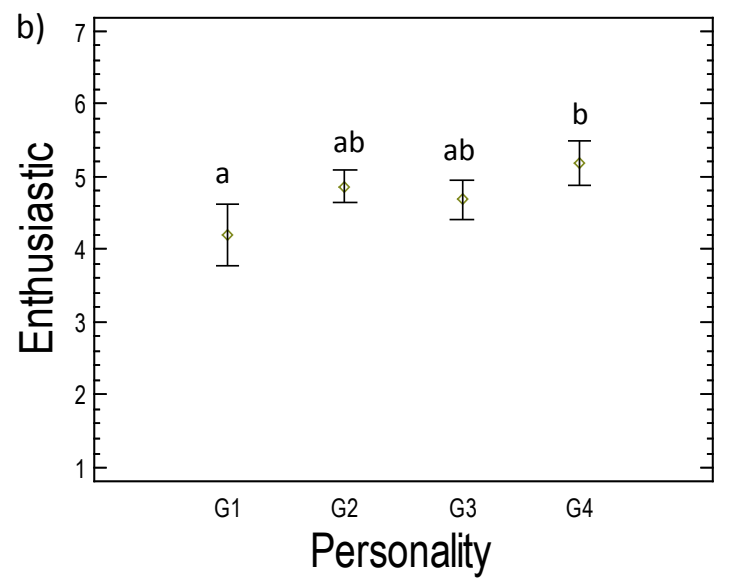

Fig. 3. Effect of the personality group (G1-G4) on the emotions enthusiastic (a) and bored (b) elicited by wine samples. Personality groups not sharing the same letter are significantly different ( $\mathrm{p}$-value $\leq 0.05$ ). 
Biplot (axes F1 and F2: 97,46 \%)

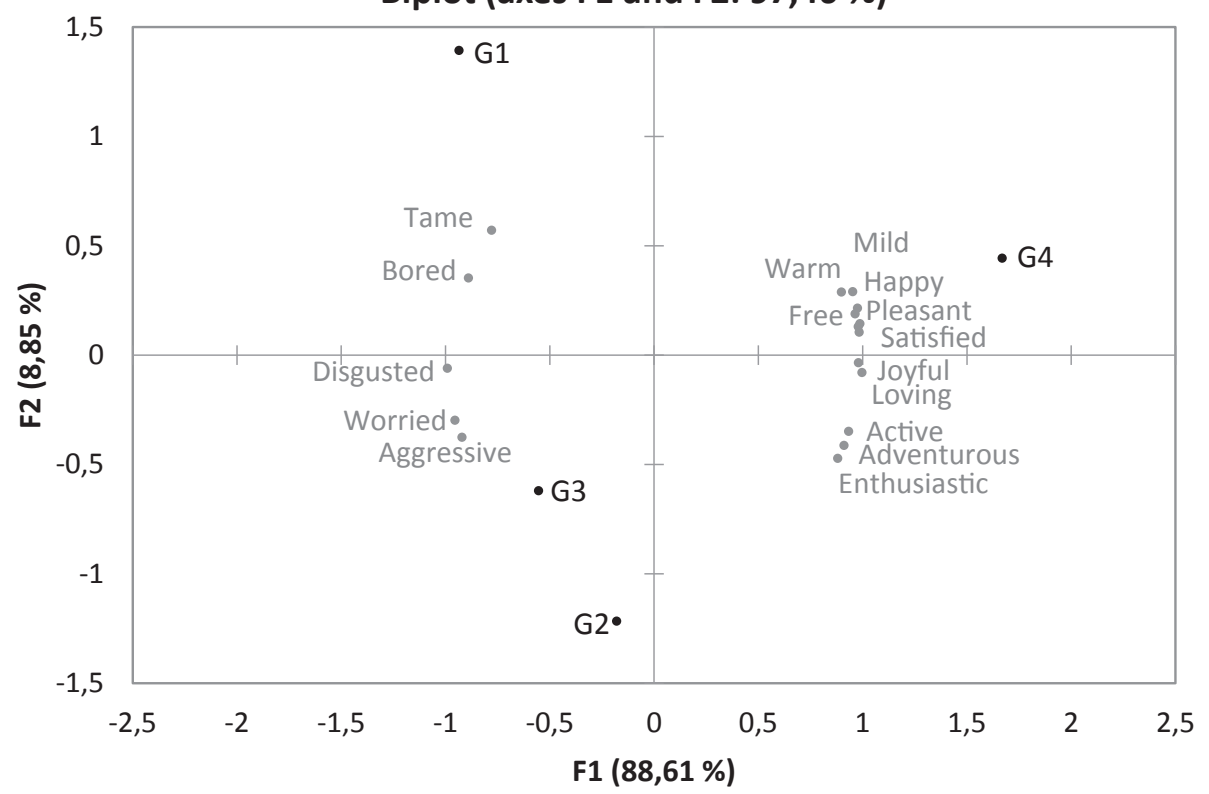

Fig. 5. Principal Component Analysis biplot of personality groups and emotions.

The present study revealed a personality effect on the hedonic response. Samant and Seo (2018) did not find significant differences between personality clusters, high neuroticism and high extraversion, in the liking of basic taste solutions. Differences between both studies could be due to the nature and complexity of the stimuli. The present study was carried out with commercial wines, with very different profiles on appearance, taste, aroma and aftertaste attributes. Less complex stimuli, such as the basic taste solutions used by Samant and Seo (2018), could be less affected by personality traits. Future studies could confirm the relationship between complexity of the stimuli and personality effect on the hedonic response.

In the same study conducted by Samant and Seo (2018) an effect of personality on emotions elicited by basic taste solutions was found. The present study is the first one conducted with commercial products investigating emotions and personality traits. Results showed that G4 reported higher ratings on positive emotions, while G1 reported higher scores on negative emotions. This response could be related with the Neuroticism and the Extraversion dimensions: Neuroticism was rated higher by G1 and lower by G4, and Extraversion was scored higher by G4 than by G1. These results were consistent with the studies carried out by Ng (2009) and Larsen and Ketelaar (1991), who found that people high in Neuroticism reacted more strongly to negative stimuli than those low in Neuroticism, and those with high Extraversion reacted more strongly to positive stimuli. Ng (2009) also found that individuals high in neuroticism showed a significant decrease on positive emotions in an unpleasant situation. The author pointed out the need to investigate across pleasant situations of differing intensities (from neutral to extremely pleasant), and to confirm the effect of neuroticism personality on positive emotions. He proposed to use a more comprehensive measure, including more emotions (he only used the terms: happiness, relief, satisfaction and pride) which comprised a wider activation range. Also, Letzring and Adamcik (2015), DeNeve and Cooper (1998a,b), and Tellegen (1985) stated that Neuroticism was positively correlated with negative affect and Extraversion was positively correlated with positive affect. Therefore, results of the present study confirmed the previous findings and emphasize the idea that the personality traits Extraversion and Neuroticism have an important influence on the emotional response (either negative or positive feelings).

Although the univariate analysis showed an effect of personality on the elicited emotions, no interactions between wine and personality segments were found. Results of the present study provided a more detailed description of the emotional response elicited by wine than the ones reported by Mora et al. (2018). Segmenting in personality groups allowed detecting another source of variation into the data, providing further and deeper understanding of the evoked emotions. Once it is verified, if this effect is not taken into consideration, the discriminant power of other effects could be decreased. Samant and Seo (2018) reported similar results, these authors found that personality traits related to Extraversion and Neuroticism affected the measurement of emotional responses, and contributed to a better prediction of liking of basic taste stimuli. However, the statistically significant personality effect does not mean causality. More research is needed to investigate the nature of relationship between personality and emotional response.

The Principal Component Analysis of the emotions elicited by wine in the personality groups showed that the projection of the emotions followed the circumplex model of emotions (Larsen \& Diener, 1992; Russel, 1980; Watson \& Tellegen, 1985), where pleasantness (horizontal axis) and engaging/activation (vertical axis) summarized the multidimensional emotional response. In this research, the term tame was located closer to negative emotions, while the term mild was closer to positive emotions. The classification of those terms by King and Meiselman (2010) was unclear, and the authors found different results depending on the product category. Results suggested that the classification of those terms might be affected by the personality traits of consumers.

The present study used EsSense25 to study the relationship between the emotional response and the personality. Considering the studied effects, results showed that 16 of the 26 emotions discriminated significantly among samples and personality groups: active, adventurous, aggressive, bored, disgusted, enthusiastic, free, happy, joyful, loving, mild, pleasant, satisfied, tame, warm and worried. Generic lexicons (King \& Meiselman, 2010; Nestrud et al., 2016; Thomson \& Crocker, 2013), such as EsSense25, have been developed to measure emotions elicited by the consumption of food products, but not for a specific product category. When studying specific product categories, the effectiveness could be slightly reduced. Up to date, the only work comparing general $v s$ product specific lexicon on wine was the one published by Silva et al. (2016). These authors compared two methods, Free Elicitation and 
EsSense Profile ${ }^{\circledast}$, concluding that a better discrimination was achieved in beer, wine, and non-alcoholic beer when using product specific emotional lexicons.

A product specific emotional lexicon should be used in future studies to confirm the association between personality traits and emotional response elicited by wines. The present research used a set of Spanish commercial wines, but more research is needed with a wider variety of wine samples and/or with other product categories to confirm the reported differences on consumers' personality segments.

\section{Conclusions}

This research was a starting point for understanding the association between product elicited feelings/emotions and personality. The main conclusion of the present study was that some personality traits (neuroticism and extraversion) could have an effect on the emotional response elicited by wine.

Clustering consumers depending on their personality might improve discrimination power of the analysis of the emotional response elicited by wines. Including this information in consumer studies could provide a deeper and further overview of the emotional response elicited by wine and/or other product categories. In particular, findings of this study should be confirmed with other product categories and/or other emotional lexicons, such as specific lexicons for wines.

BFI has proved to provide an easy way of segmenting consumers, but more research is needed to get a deeper knowledge of the effect of personality on self-reported feelings and to confirm our findings related to the neuroticism $v s$ extraverted dimension. Our results suggested that including the BFI in the screening of consumers could improve the consumers' discrimination in terms of liking and elicited emotional responses. Extraversion and Neuroticism dimensions were the personality traits more closely linked with feelings and emotions, therefore, these dimensions seemed to be the main ones to focus on further affective consumer studies.

\section{Acknowledgements}

The study was partially funded by project AGL2016-78936-R from the Spanish Ministry of Economy and Competitiveness (MINECO). Authors are grateful to all the volunteers who participated in the research.

\section{Appendix A. Supplementary data}

Supplementary data to this article can be found online at https:// doi.org/10.1016/j.foodqual.2019.03.015.

\section{References}

Addinsoft (2019). XLSTAT statistical and data analysis solution. NY, USA: Long Island. https://www.xlstat.com.

American Psychological Association (APA). (2018). Personality. https://www.apa.org/ topics/personality/ (accessed November 2, 2018).

Byrnes, N. K., \& Hayes, J. E. (2013). Personality factors predict spicy food liking and intake. Food Quality and Preference, 28(1), 213-221. https://doi.org/10.1016/J. FOODQUAL. 2012.09.008.

Cuesta, D., Chaya, C., \& Pérez, F. J. (2010). Estudio de la respuesta emocional del consumidor español de vino. Vitoria, País Vasco: Universidad del País Vasco (UPV-EHU).

Damasio, A. R. (2006). Descartes' error: Emotion, reason and the human brain. Vintage.

DeNeve, K. M., \& Cooper, H. (1998a). The happy personality: A meta-analysis of 137 personality traits and subjective well-being. Psychological Bulletin, 124(2), 197. https://doi.org/10.1037//0033-2909.124.2.197.

DeNeve, K. M., \& Copper, H. (1998b). The happy personality: A meta-analysis of 137 personality traits and subjective well-being. Psychological Bulletin, 124(2), 197-229. https://www.gwern.net/docs/iq/1998-deneve.pdf.

Dorado, R., Pérez-Hugalde, C., Picard, A., \& Chaya, C. (2016). Influence of first position effect on emotional response. Food Quality and Preference, 49, 189-196. https://doi. org/10.1016/j.foodqual.2015.12.009.

Goldberg, L. R. (1990). An alternative "description of personality": The big-five factor structure. Journal of Personality and Social Psychology, 52, 1216-1229. http:// cmapspublic2.ihmc.us/rid =1LQBQ96VY-19DH2XW-GW/Goldberg.Big-Five-
FactorsStructure.JPSP.1990.pdf.

Herz, R. S. (2005). Odor-associative learning and emotion: Effects on perception and behavior. Chemical Senses, 30(Supplement 1), i250-i251. https://doi.org/10.1093/ chemse/bjh209.

Herz, R. S. (2011). PROP taste sensitivity is related to visceral but not moral disgust. Chemosensory Perception, 4(3), 72-79. https://doi.org/10.1007/s12078-011-9089-1.

John, O. P., \& Srivastava, S. (1999). The Big Five trait taxonomy: History, measurement, and theoretical perspectives. Handbook of Personality: Theory and Research, 2(1999), $102-138$.

John, O. P. (2007). Berkeley Personality Lab. https://www.ocf.berkeley.edu/ johnlab/ index.htm (accessed November 9, 2018).

Keller, C., \& Siegrist, M. (2015). Does personality influence eating styles and food choices? Direct and indirect effects. Appetite, 84, 128-138. https://doi.org/10.1016/ j.appet.2014.10.003.

King, S. C., \& Meiselman, H. L. (2010). Development of a method to measure consumer emotions associated with foods. Food Quality and Preference, 21(2), 168-177. https:// doi.org/10.1016/j.foodqual.2009.02.005.

King, S. C., Meiselman, H. L., \& Thomas Carr, B. (2013). Measuring emotions associated with foods: Important elements of questionnaire and test design. Food Quality and Preference, 28(1), 8-16. https://doi.org/10.1016/j.foodqual.2012.08.007.

Köster, E. P. (2009). Diversity in the determinants of food choice: A psychological perspective. Food Quality and Preference, 20(2), 70-82. https://doi.org/10.1016/j. foodqual.2007.11.002.

Larsen, R. J., \& Diener, E. (1992). Promises and problems with the circumplex model of emotion.

Larsen, R. J., \& Ketelaar, T. (1991). Personality and susceptibility to positive and negative emotional states. Journal of Personality and Social Psychology, 61(1), 132. https://doi. org/10.1037//0022-3514.61.1.132.

Letzring, T. D., \& Adamcik, L. A. (2015). Personality traits and affective states: Relationships with and without affect induction. Personality and Individual Differences, 75, 114-120. https://doi.org/10.1016/j.paid.2014.11.011.

Mojet, J. (2001). No Title. Wageningen, The Netherlands: Internal Report Wageningen University and Research Center.

Mora, M., Urdaneta, E., \& Chaya, C. (2018). Emotional response to wine: Sensory properties, age and gender as drivers of consumers' preferences. Food Quality and Preference, 66. https://doi.org/10.1016/j.foodqual.2017.12.015.

Nestrud, M. A., Meiselman, H. L., King, S. C., Lesher, L. L., \& Cardello, A. V. (2016) Development of EsSense25, a shorter version of the EsSense Profile ${ }^{\circledast}$. Food Quality and Preference, 48(Part A), 107-117. https://doi.org/10.1016/j.foodqual.2015.08.005.

$\mathrm{Ng}$, W. (2009). Clarifying the relation between neuroticism and positive emotions. Personality and Individual Differences, 47(1), 69-72. https://doi.org/10.1016/j.paid. 2009.01.049.

Prescott, J. (2017). Some considerations in the measurement of emotions in sensory and consumer research. Food Quality and Preference, 62, 360-368. https://doi.org/10. 1016/j.foodqual.2017.04.005

Robino, A., Mezzavilla, M., Pirastu, N., La Bianca, M., Gasparini, P., Carlino, D., \& Tepper, B. J. (2016). Understanding the role of personality and alexithymia in food preferences and PROP taste perception. Physiology \& Behavior, 157, 72-78. https://doi. org/10.1016/J.PHYSBEH.2016.01.022.

Russel, J. A. (1980). A circumplex model of affect. Journal of Personality and Social Psychology, 39, 1161-1178. https://doi.org/10.1037/h0077714.

Samant, S. S., \& Seo, H.-S. (2018). Personality traits affect the influences of intensity perception and emotional responses on hedonic rating and preference rank toward basic taste solutions. Journal of Neuroscience Research. https://doi.org/10.1002/jnr. 24321.

Scott, N. O., Burgess, B., \& Tepper, B. J. (2019). Perception and liking of soups flavored with chipotle chili and ginger extracts: Effects of PROP taster status, personality traits and emotions. Food Quality and Preference, 73, 192-201. https://doi.org/10.1016/J. FOODQUAL.2018.11.009.

Silva, A. P., Jager, G., Van Zyl, H., Voss, H., Pintado, M., Hogg, T., \& de Graaf, C. (2016). Comparing two methods to measure emotions elicited by beer, wine and non-alcoholic beer. Appetite, 101, 236. https://doi.org/10.1016/j.appet.2016.02.133.

Spinelli, S. (2017). Implications of the science of emotion for applied research: Comments on Prescott (2017). Food Quality and Preference, 62, 369-371. https://doi.org/10. 1016/j.foodqual.2017.05.013.

Spinelli, S., De Toffoli, A., Dinnella, C., Laureati, M., Pagliarini, E., Bendini, A., .. Monteleone, E. (2018). Personality traits and gender influence liking and choice of food pungency. Food Quality and Preference, 66, 113-126. https://doi.org/10.1016/J. FOODQUAL.2018.01.014.

Stone, L. J., \& Pangborn, R. M. (1990). Preferences and intake measures of salt and sugar, and their relation to personality traits. Appetite, 15(1), 63-79. https://doi.org/10. 1016/0195-6663(90)90100-M.

Sugiyama, H., Oshida, A., Thueneman, P., Littell, S., Katayama, A., Kashiwagi, M., ... Herz, R. S. (2015). Proustian products are preferred: The relationship between odorevoked memory and product evaluation. Chemosensory Perception, 8(1), 1-10. https://doi.org/10.1007/s12078-015-9182-y.

Tellegen, A. (1985). Structures of mood and personality and their relevance to assessing anxiety, with an emphasis on self-report. Anxiety and the anxiety disorders (pp. 681706). Hillsdale, NJ, US: Lawrence Erlbaum Associates Inc.

Thomson, D. M. H., \& Crocker, C. (2013). A data-driven classification of feelings. Food Quality and Preference, 27(2), 137-152. https://doi.org/10.1016/j.foodqual.2012.09. 002 .

Torrico, D. D., Fuentes, S., Gonzalez Viejo, C., Ashman, H., Gunaratne, N. M., Gunaratne, T. M., \& Dunshea, F. R. (2018). Images and chocolate stimuli affect physiological and affective responses of consumers: A cross-cultural study. Food Quality and Preference, 65, 60-71. https://doi.org/10.1016/J.FOODQUAL.2017.11.010. 
Ullrich, N. V., Touger-Decker, R., O’Sullivan-Maillet, J., \& Tepper, B. J. (2004). PROP taster status and self-perceived food adventurousness influence food preferences. Journal of the American Dietetic Association, 104(4), 543-549. https://doi.org/10. 1016/J.JADA.2004.01.011.

Wakeling, I. N., \& MacFie, H. J. H. (1995). Designing consumer trials balanced for first and higher orders of carry-over effect when only a subset of k samples from t may be tested. Food Quality and Preference, 6(4), 299-308. https://doi.org/10.1016/0950-
3293(95)00032-1.

Watson, D., \& Tellegen, A. (1985). Toward a consensual structure of mood. Psychological Bulletin, 98, 219-235.

Yeomans, M. R., Prescott, J., \& Gould, N. J. (2009). Acquired hedonic and sensory characteristics of odours: Influence of sweet liker and propylthiouracil taster status. Quarterly Journal of Experimental Psychology, 62(8), 1648-1664. https://doi.org/10. 1080/17470210802557793. 